\title{
Fuzzy Goal Programming Approach to Solve Linear Multilevel Programming Problems using Genetic Algorithm
}

\author{
Papun Biswas \\ Department of Electrical Engineering \\ JIS College of Engineering \\ Kalyani-741235 \\ West Bengal, India
}

\author{
Bijay Baran Pal \\ Department of Mathematics \\ University of Kalyani \\ Kalyani-741235 \\ West Bengal, India
}

\begin{abstract}
This paper introduces a priority based fuzzy goal programming (FGP) method for modelling and solving multilevel programming problem (MLPP) through genetic algorithm (GA). In model formulation, the individual best solution of objectives of each of the decision makers (DMs) is determined by using the GA method for fuzzy description of the objectives. Then, tolerance membership functions of the defined fuzzy goals are constructed for measuring the degree of satisfaction of goal achievement and there by degree of optimality of the decision vectors controlled by the higher level DMs. In the executable FGP model, minimization of the under-deviational variables of the defined membership goals with highest membership value (unity) as the aspiration levels of them on the basis of preemptive priority is taken into consideration in the decision making context. In the solution process, sensitivity analysis with variations of priority structure of model goals is performed and then Euclidean distance function is used to identify the appropriate priority structure under which the most satisfactory decision can be reached in the decision making horizon.
\end{abstract}

In the proposed GA scheme, roulette-wheel selection scheme, single point crossover and uniform mutation are adopted in the decision search process with regard to reach a satisfactory solution in the proposed hierarchical decision system.

The effective use of the proposed approach is illustrated through a numerical example. Performance comparisons are also made to highlight the superiority of the proposed approach over the approaches studied previously.

\section{Keywords}

Euclidean Distance, Fuzzy Programming, Fuzzy Goal Programming, Genetic Algorithm, Goal Programming, Multilevel Programming.

\section{INTRODUCTION}

In the field of mathematical programming (MP), multilevel programming (MLP) [1] was developed to solve decentralized planning problems with multiple DMs in a hierarchical decision making organization.

In MLPP, the execution of the decision power is sequential from a higher level to lower level, and each DM tries to optimize his own benefit under a conflicting environment in the hierarchical levels.
The concept of hierarchical decision problem as a special field of study in the area of MP was first suggested by Burton and Obel [2] in 1977. During 1980s, a considerable number of solution approaches for MLPPs as well as bilevel programming problems (BLPPs) [3] as a special case of MLPP have been deeply studied in $[4,5,6]$ by pioneer researchers in this field.

But, in the real-life decision situations, it may be mentioned that the previous approaches are computationally not very efficient, especially for large and complex hierarchical decision problems. In most of the classical approaches for solving hierarchical decision problems developed so far, it was found that the decision power of a higher level DM is often dominated by a lower level DM.

However, in hierarchical decision structure of a decentralized decision system, it is generally assumed that the DMs cooperative each other to reach a minimum level of satisfaction for smooth running the activities of the organization. In such a situation, the fuzzy programming (FP) [7] approach based on the concept of fuzzy set theory (FST) [8] has been introduced to solve hierarchical decision problems [9].

But, due to conflicting in nature of objectives, there is a possibility of rejecting the solution again and again by followers and re-evaluation of the problem with elicited membership values of the membership functions is repeatedly involved in the solution search process. As a result, decision deadlock often arises in a decision making situation. Thereafter, the supervised search procedure with use of $\max$-min operator introduced by Bellman and Zadeh [10] was studied in [11] to solve such decision problems. The conventional FP approach have been further extended by Shih and Lee [12] in 2000 to solve hierarchical decision problems from the view point of making a balance of decision powers of DMs in the decision making context. In using such an approaches, the elicited membership functions for the fuzzy goals are also need be redefined again and again to reach a satisfactory decision in the solution search process.

To avoid the computational difficulty with a FP approach, FGP approach [13] as an extension of conventional goal programming (GP) [14] that is based on the 'goal satisficing philosophy' [15], has been studied in [16] for making decision with regard to achievement of multiple fuzzy goals in uncertain environment. The FGP based solution approach to BLPPs has been studied in [17] and further extended to solve MLPPs in 
[18] in the past. However, the extensive study on fuzzy MLPPs is at an early stage.

Now, GAs based on natural selection and population genetics, initially introduced by Holland [19] in 1973, have appeared as flexible and robust computational tools for searching solutions of different real-world multiobjective decision problems [20]. The GA based solution approaches to decision problems in the framework of GP have been studied [21] in the past. The uses of GAs to FP formulations of BLPPs as well as MLPPs have also been studied [22,23] by pioneer researchers in the field. However, the GA based solution method to the FGP formulations of BLPPs as well as MLPPs is yet to be widely circulated in the literature.

In the present article, a FGP procedure for modelling and solving MLPPs by using a GA scheme is presented for solving large hierarchical decision problems in uncertain environment.

\section{MLPP PROBLEM FORMULATION}

In the hierarchical decision situation, let $\mathrm{X}\left(\mathrm{X}_{1}, \mathrm{X}_{2}, \ldots ., \mathrm{X}_{\mathrm{n}}\right)$ be the vector of decision variables that are associated with different levels of the decision problem. Then, let $\mathrm{Z}_{l}$ be the objective function and $X_{l}$ be the control vector of decision variables at the $l$-th $\quad$ level $\quad \mathrm{DM}, \quad l=1,2, \ldots, L ; L \leq \mathrm{n}$ where $\cup_{l}\left\{\mathrm{X}_{l} \mid l=1,2, \ldots, L\right\}=\mathrm{X}$

Then, the general framework of a MLPP within a hierarchical nested decision structure can be presented as follows.

Find $\mathrm{X}\left(\mathrm{X}_{1}, \mathrm{X}_{2}, \ldots, \mathrm{X}_{\mathrm{L}}\right)$ so as to:

$$
\underset{\mathrm{X}_{1}}{\operatorname{Maximize}} \mathrm{Z}_{1}(\mathrm{X})=\sum_{l=1}^{L} \mathrm{c}_{1 l} \mathrm{X}_{l}
$$

where, for given $\mathrm{X}_{1} ; \mathrm{X}_{2}, \mathrm{X}_{3}, \ldots, \mathrm{X}_{L}$ solve

$$
\underset{\mathrm{X}_{2}}{\operatorname{Maximize}} \mathrm{Z}_{2}(\mathrm{X})=\sum_{l=1}^{L} \mathrm{c}_{2 l} \mathrm{X}_{l}
$$

(Second-level)

where, for given $\mathrm{X}_{1}$ and $\mathrm{X}_{2} ; \mathrm{X}_{3}, \mathrm{X}_{4}, \ldots, \mathrm{X}_{L}$ solve

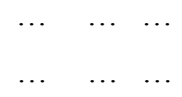

where, for given $\mathrm{X}_{1}, \mathrm{X}_{2}, \ldots, \mathrm{X}_{L-1} ; \mathrm{X}_{L}$ solves

$$
\underset{\mathrm{X}_{L}}{\operatorname{Maximize}} \mathrm{Z}_{L}(\mathrm{X})=\sum_{l=1}^{L} \mathrm{c}_{L l} \mathrm{X}_{l}
$$

subject to $\left(\mathrm{X}_{1}, \mathrm{X}_{2}, \ldots, \mathrm{X}_{L}\right) \in \mathrm{S}=\left\{\sum_{l=1}^{L} \mathrm{~A}_{l} \mathrm{X}_{l} \leq \mathrm{b}\right\}, \mathrm{X}_{l} \geq 0$,

$$
l=1,2, \ldots, L
$$

where, $\mathrm{b}$ are constant vectors, $\mathrm{A}_{l}(l=1,2, \ldots, L)$ are constant matrices. It is also assumed that $\mathrm{S}(\neq \Phi)$ is bounded.

Now, it is to be observed that the problem (1) is multiobjective in nature and the execution of decision power of the DMs is sequential from top-level to bottom-level.
In the classical approaches of MLPPs, it is to be noted that the decision $X_{l+1}$ is made by a lower-level DM subject to the decision $X_{l}$ made by the respective higher level DM in the order of their hierarchy. But in such a hierarchical execution process for making decision, the lower level DMs are always found to be dominated by higher level DMs. As a consequence, decision deadlock arises frequently in most of the decision situations owing to rejection of solution by lower level DMs.

To overcome the above situation, relaxations of individual decision as well as the objective value up to certain tolerance limits of each of the higher level DMs are needed essentially to execute the decision powers of DMs properly and thereby making overall benefit of the organization.

Now, to develop the fuzzy goals of the problem and then to solve it under the framework of FGP, a GA scheme is introduced in section 3 .

\section{GA FOR MLPP}

The solution methods based on GAs for multiobjective decision analysis within the frameworks of conventional GP and FGP have been investigated by Zheng et al. [24] and Gen et al. [25] in the past. The efficient uses of GA approaches to different real-life multiobjective decision making (MODM) problems have also been studied by Sakawa and Kobuta (2000) [26], Taguchi et al. (1998) [27] and Wang (2002) [28] previously.

However, in the proposed GA scheme, the initial population (the initial feasible solution individuals) is generated randomly with the condition of satisfying the system constraints in the solution search process.

The feasible solution individuals are then evaluated for their fitness to evaluate the achievement function associated with the problem.

Now, in the literature of GAs, there are large numbers of schemes [19] for generating new population with the use of different operators: selection, crossover and mutation.

The steps of the GA procedure with the core functions adopted in the solution process are presented via the following algorithmic steps.

\section{The GA Algorithm:}

\section{Step1. Representation and initialization}

Let $\mathrm{E}$ denote the double vector representation of chromosome in a population as $\mathrm{E}=\left\{\mathrm{x}_{1}, \mathrm{x}_{2}, \ldots, \mathrm{x}_{\mathrm{n}}\right\}$. The population size is defined by pop_size, and pop_size chromosomes are randomly initialized in its search domain.

\section{Step2. Fitness function}

The fitness value of each chromosome is judged by the value of an objective function. The fitness function is defined as:

$\operatorname{eval}\left(\mathrm{E}_{v}\right)=\left(\mathrm{Z}_{l}\right)_{v}, l=1,2, \ldots, L ; \quad v=1,2, \ldots$, pop_size

where $\mathrm{Z}_{l}$ represents the objective function of the $l$-th level DM given by (1) and the subscript $v$ in (2) refers to the fitness value of the selected $v$-th chromosome, $v=1,2, \ldots$, pop_size. The best chromosome with largest fitness value at each generation is determined as:

$\mathrm{E}^{*}=\max \left\{\operatorname{eval}\left(\mathrm{E}_{v}\right) \mid v=1,2, \ldots\right.$, pop_size $\}$, 
or,

$\mathrm{E}^{*}=\min \left\{\right.$ eval $\left(\mathrm{E}_{v}\right) \mid v=1,2, \ldots$, pop_size $\}$,

depending on searching of the best or worst value of an objective.

\section{Step3. Selection}

The simple roulette-wheel scheme [29] is used for selecting two parents for mating purpose in the genetic search process.

\section{Step4. Crossover}

The parameter $p_{c}$ is defined as the probability of crossover. The single point crossover operation [29] of a genetic system is applied here in the sense that the resulting offspring always satisfy the linear constraints set $\mathrm{S}(\neq \phi)$. Here, a chromosome is selected as a parent, if for a defined random number $\mathrm{r} \in[0,1], \mathrm{r}<\mathrm{p}_{\mathrm{c}}$ is satisfied.

For example, for two parents $\mathrm{E}_{1}, \mathrm{E}_{2} \in \mathrm{S}$, arithmetic crossover is defined as:

$$
\mathrm{E}_{1}^{1}=\alpha_{1} \mathrm{E}_{1}+\alpha_{2} \mathrm{E}_{2}, \mathrm{E}_{2}^{1}=\alpha_{2} \mathrm{E}_{1}+\alpha_{1} \mathrm{E}_{2} \text {, for producing two }
$$

offspring $E_{1}^{1}$ and $E_{2}^{1}$, where $\alpha_{1}, \alpha_{2} \geq 0$ with $\alpha_{1}+\alpha_{2}=1$,

$\mathrm{E}_{1}^{1}, \mathrm{E}_{2}^{1} \in \mathrm{S}$.

\section{Step5. Mutation}

As in the conventional GA scheme, a parameter $\mathrm{p}_{\mathrm{m}}$ of the genetic system is defined as the probability of mutation. The mutation operation is performed on a uniform basis, where for a random number $r \in[0,1]$, a chromosome is selected for mutation provided that $\mathrm{r}<\mathrm{p}_{\mathrm{m}}$.

\section{Step6. Termination}

The execution of the whole process terminates when the fittest chromosome is reported at a certain generation number in the solution search process.

The pseudo code of the standard genetic algorithm is presented as follows:

\section{Initialize population of chromosomes $E(x)$}

Evaluate the initialized population by computing its fitness measure

\section{While not termination criteria do}

$x:=x+1$

Select $E(x+1)$ from $E(x)$

Crossover $E(x+1)$

Mutate $E(x+1)$

Evaluate $E(x+1)$

End While

Now, the FGP formulation of the problem (1) by defining the fuzzy goals is presented in section 4 .

\section{FORMULATION OF FGP MODEL}

To formulate the FGP model of the given problem, the imprecise aspiration levels of the objectives of DMs located at all the levels and the decision vectors of upper level DMs as well as the tolerance limits for achieving the respective aspired levels are determined first. Then, they are characterized by their membership functions for measuring the degree of achievement of the aspired goal levels in the decision situation.

In the present decision situation, the individual best decisions of the DMs are taken into consideration and they are evaluated by using the proposed GA scheme.

Let $\left(\mathrm{X}_{1}^{l}, \mathrm{X}_{2}^{l}, \ldots, \mathrm{X}_{\mathrm{I}}^{l} ; \mathrm{Z}_{l}^{*}\right)$ be the best decision of the $l$-th level DM,

where $Z_{l}^{*}=\max _{\mathrm{X} \in \mathrm{S}} \mathrm{Z}_{l}(\mathrm{X})$.

Then the fuzzy goal objectives can be presented as:

$$
\mathrm{Z}_{l} \gtrsim \mathrm{Z}_{l}^{*}, \quad l=1,2, \ldots, L .
$$

Similarly, the fuzzy goals for the control vectors of the upperlevel DMs appear as:

$$
\mathrm{X}_{l} \gtrsim \mathrm{X}_{l}^{l}, \quad l=1,2, \ldots, L-1 .
$$

Now, from the view point of considering the relaxation made by an upper-level DM for the benefit of a lower-level DM, the lower-tolerance limit for the $l$-th fuzzy goal $Z_{l}$ can be determined as:

$$
\mathrm{Z}_{l}^{l+1}\left[=\mathrm{Z}_{l}\left(\mathrm{X}_{1}^{l+1}, \mathrm{X}_{2}^{l+1}, \ldots, \mathrm{X}_{L}^{l+1}\right)\right]<\mathrm{Z}_{\mathrm{i}}^{*}, \quad l=1,2, \ldots, L-1 .
$$

Again, since the $L$-th level DM is at the bottom level, the lowertolerance limit of the objective $\mathrm{Z}_{L}$ can be determined as:

$$
\mathrm{Z}_{L}^{\mathrm{m}}\left[=\min \left(\mathrm{Z}_{l}\left(\mathrm{X}_{1}^{l}, \mathrm{X}_{2}^{l}, \ldots, \mathrm{X}_{L}^{l}\right) ; l=1,2, \ldots,(L-1)\right]<\mathrm{Z}_{L}^{*}\right.
$$

Now, since the DMs are motivated to co-operate each other and a certain relaxation on the decision of each of the upper-level DMs is made for the benefit of a lower level DM, the lower tolerance limit of the decision $\mathrm{X}_{l}$ can be determined as:

$$
\mathrm{X}_{l}^{\mathrm{n}}\left(\mathrm{X}_{l}^{l+1}<\mathrm{X}_{l}^{\mathrm{n}}<\mathrm{X}_{l}^{l}\right), 1=1,2, \ldots,(L-1) .
$$

The construction of the membership functions of the defined fuzzy goals is presented in section 4.1.

\subsection{Construction of Membership Function}

For the defined lower-tolerance limits of the fuzzy goals, the membership functions can be constructed as follows.

$$
\mu_{\mathrm{Z}_{l}}\left[\mathrm{Z}_{l}(\mathrm{X})\right]=\left\{\begin{array}{cl}
1 & \text {;if } \mathrm{Z}_{l}(\mathrm{X}) \geq \mathrm{Z}_{l}^{*}, \\
\frac{\mathrm{Z}_{l}(\mathrm{X})-\mathrm{Z}_{l}^{l+1}}{\mathrm{Z}_{l}^{*}-\mathrm{Z}_{l}^{l+1}} & \text {;if } \mathrm{Z}_{l}^{l+1} \leq \mathrm{Z}_{l}(\mathrm{X})<\mathrm{Z}_{l}^{*}, \\
0 & \text {;if } \mathrm{Z}_{l}(\mathrm{X})<\mathrm{Z}_{l}^{l+1}, \quad l=1,2, \ldots,(L-1) .
\end{array}\right.
$$

$$
\mu_{\mathrm{Z}_{L}}\left[\mathrm{Z}_{L}(\mathrm{X})\right]=\left\{\begin{array}{cl}
1 & \text {;if } \mathrm{Z}_{L}(\mathrm{X}) \geq \mathrm{Z}_{L}^{*}, \\
\frac{\mathrm{Z}_{L}(\mathrm{X})-\mathrm{Z}_{L}^{\mathrm{m}}}{\mathrm{Z}_{L}^{*}-\mathrm{Z}_{L}^{\mathrm{m}}} & ; \text { if } \mathrm{Z}_{L}^{\mathrm{m}} \leq \mathrm{Z}_{L}(\mathrm{X})<\mathrm{Z}_{L}^{*}, \\
0 & ; \text { if } \mathrm{Z}_{\mathrm{L}}(\mathrm{X})<\mathrm{Z}_{\mathrm{L}}^{\mathrm{m}},
\end{array}\right.
$$




$$
\mu_{\mathrm{X}_{l}}\left[\mathrm{X}_{1}\right]=\left\{\begin{array}{cl}
1 & \text {;if } \mathrm{X}_{l} \geq \mathrm{X}_{l}^{l}, \\
\frac{\mathrm{X}_{l}-\mathrm{X}_{l}^{\mathrm{n}}}{\mathrm{X}_{l}^{l}-\mathrm{X}_{l}^{\mathrm{n}}} & \text {;if } \mathrm{X}_{l}^{\mathrm{n}} \leq \mathrm{X}_{l}<\mathrm{X}_{l}^{l}, \\
0 & \text {;if } \mathrm{X}_{l}<\mathrm{X}_{l}^{\mathrm{n}}, \quad l=1,2, \ldots, L-1 .
\end{array}\right.
$$

The graphical representation of linear membership function associated with the problem in (3) is displayed in Fig. 1.

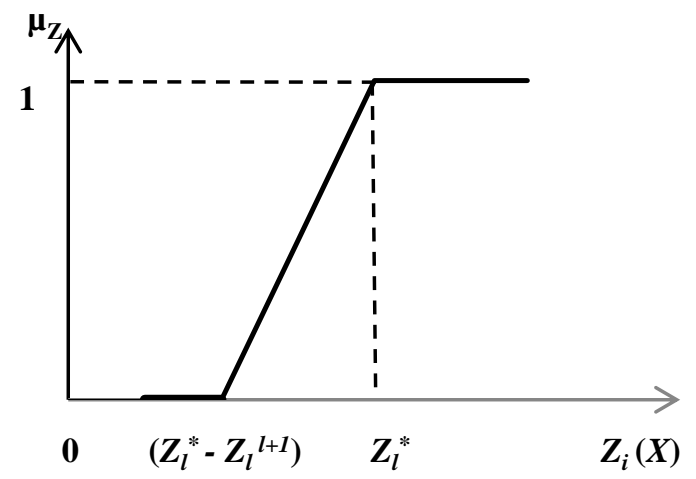

Fig 1: Graphical representation of the membership function of fuzzy goal in (3)

Now, the FGP model formulation is presented in the following section 4.2 .

\subsection{FGP Model Formulation of MLPP}

In the FGP model formulation, the membership functions are transformed into goals by assigning the aspiration level unity and introducing under- and over-deviational variables to each of them. Then, achievement of the aspired goal levels to the extent possible by minimizing the sum of the weighted underdeviational variables in the goal achievement function on the basis of weights of importance of achieving the goals is taken into account.

Now, since a considerable number of fuzzy goals are involved with the problem and they usually conflict among themselves, it seems that the FGP formulation of the problem on the basis of priority of DMs' needs and desires is effective in the present decision situation.

In priority based FGP, the goals are rank ordered on the basis of the priorities of achieving the target levels of them. The goals which seem to be equally important from the view point of assigning a priority are included at the same priority level and numerical weights are given to them on the basis of their weights of importance of achieving their aspired levels at the same priority level.

Then, a priority based FGP [30] model of the problem is presented as follows.

Find $\left(\mathrm{X}_{1}, \mathrm{X}_{2}, \ldots, \mathrm{X}_{L}\right)$ so as to:

Minimize $Z=\left[P_{1}\left(d^{-}\right), P_{2}\left(d^{-}\right), P_{r}\left(d^{-}\right), \ldots, P_{R}\left(d^{-}\right)\right]$

and satisfy,

$$
\begin{aligned}
& \mu_{\mathrm{Z}_{l}}: \frac{\mathrm{Z}_{l}(\mathrm{X})-\mathrm{Z}_{l}^{l+1}}{\mathrm{Z}_{l}^{*}-\mathrm{Z}_{l}^{l+1}}+\mathrm{d}_{l}^{-}-\mathrm{d}_{l}^{+}=1, \quad l=1,2, \ldots, L-1 . \\
& \mu_{\mathrm{Z}_{L}}: \frac{\mathrm{Z}_{L}(\mathrm{X})-\mathrm{Z}_{\mathrm{L}}^{\mathrm{m}}}{\mathrm{Z}_{\mathrm{L}}^{*}-\mathrm{Z}_{\mathrm{L}}^{\mathrm{m}}}+\mathrm{d}_{L}^{-}-\mathrm{d}_{L}^{+}=1 \\
& \mu_{\mathrm{X}_{l}}: \frac{\mathrm{X}_{l}-\mathrm{X}_{l}^{\mathrm{n}}}{\mathrm{X}_{l}^{l}-\mathrm{X}_{l}^{\mathrm{n}}}+\mathrm{d}_{i}^{-}-\mathrm{d}_{i}^{+}=\mathrm{I}_{i}, \quad i=L+l, \text { where } \\
& l=1,2, \ldots, L-1 . \\
& \mathrm{d}_{l}^{+}, \mathrm{d}_{l}^{-} \geq 0, \quad \mathrm{~d}_{i}^{+}, \mathrm{d}_{i}^{-} \geq 0,1=1,2, \ldots, L .
\end{aligned}
$$

subject to the given system constraints in (2.1), $\mathrm{Z}$ represents the vectors of the $K$ priority achievement functions and $\mathrm{d}_{l}^{+}, \mathrm{d}_{l}^{-}(l=1,2, \ldots, L)$ represent the over- and under-deviational variables, respectively, and $\mathrm{d}_{i}^{+}, \mathrm{d}_{i}^{-} \geq 0$, are the vectors of overand under-deviational variables associated with the respective goals, $\mathrm{I}_{i}$ are column vectors with all elements equal to 1. $\mathrm{P}_{\mathrm{r}}\left(\mathrm{d}^{-}\right)$is a linear function of the weighted under-deviational variables at the $r$-th priority level and where $\mathrm{P}_{\mathrm{r}}\left(\mathrm{d}^{-}\right)$is of the form:

$\mathrm{P}_{\mathrm{r}}\left(\mathrm{d}^{-}\right)=\sum_{l=1}^{L} \mathrm{w}_{\mathrm{rl} l}^{-} \mathrm{d}_{\mathrm{rl}}^{-}+\sum_{l=\mathrm{R}+1}^{2 R-1} \mathrm{w}_{\mathrm{ri}}^{-} \mathrm{d}_{\mathrm{ri}}^{-}$,

where $\mathrm{d}_{\mathrm{rl}}^{-}$and $\mathrm{d}_{\mathrm{ri}}^{-}$are renamed for $\mathrm{d}_{l}^{-}$and $\mathrm{d}_{i}^{-}$to represent them at the $\mathrm{r}$-th priority level. $\mathrm{w}_{\mathrm{rl}}^{-}(\geq 0)$ and $\mathrm{w}_{\mathrm{ri}}^{-}(\geq 0)$ are the numerical weights and the vector of numerical weights, respectively, and they are determined as [31]:

$$
\begin{aligned}
& \mathrm{w}_{\mathrm{r} l}^{-}=\frac{1}{\left(\mathrm{Z}_{l}^{*}-\mathrm{Z}_{l}^{l+1}\right)_{\mathrm{k}}}, l=1,2, \ldots, \mathrm{L}-1, \\
& \mathrm{w}_{\mathrm{r} L}^{-}=\frac{1}{\left(\mathrm{Z}_{L}^{*}-\mathrm{Z}_{L}^{\mathrm{m}}\right)_{\mathrm{r}}}, \\
& \mathrm{w}_{\mathrm{r} i}^{-}=\frac{1}{\left(\mathrm{X}_{l}^{l}-\mathrm{X}_{l}^{\mathrm{n}}\right)_{\mathrm{r}}}, \quad \mathrm{i}=L+l, \text { where } l=1,2, \ldots, L-1,
\end{aligned}
$$

where the suffix ' $r$ ' is used to represent the values of the weights of achieving the aspired goal values at the r-th priority level.

It is worthy to mention here that the notion of pre-emptive priorities of the goals actually holds on the concept that the goals which are included at the $r$-th priority level $P_{r}$ are preferred most for achievement of their aspired levels before considering the achievement problem of the goals of the next priority $\mathrm{P}_{\mathrm{r}+1}$, regardless of any multiplier associated with $\mathrm{P}_{\mathrm{r}+1}$.

Also, the relationship among the priorities is

$$
\mathrm{P}_{1} \gg>\mathrm{P}_{2} \gg \gg, \ldots \gg \mathrm{P}_{\mathrm{r}} \gg \gg, \ldots \gg \mathrm{P}_{\mathrm{R}},
$$

where $>>>$ means 'much greater than' and implies that the goals at the first priority level $\left(\mathrm{P}_{1}\right)$ are achieved to the extent possible before considering the achievement of goals at the second priority level $\left(\mathrm{P}_{2}\right)$, and so forth.

Now, in a decision making situation, achievement of the highest membership value of each of the fuzzy goals is a trivial one. 
Again, a DM is frequently confused with that of assigning the proper priorities to the goals, because they often conflict each other for achieving their individual aspired levels in the decision making environment.

To overcome the above situation, the notion of Euclidean distance function [32] for group decision analysis, introduced in the preceding chapter is used here to achieve an ideal point dependent solution and thereby selecting the appropriate priority structure under which the most satisfactory decision can be reached.

The selection of appropriate priority structure for goal achievement is presented in the following section 4.3.

\subsection{Priority Structure Selection}

In the present decision situation, since the highest membership value of each fuzzy goal is unity, the ideal point would be a vector with each element equal to 1 .

The Euclidean distance function can be presented as:

$$
\begin{array}{r}
\mathrm{D}^{\mathrm{r}}=\left[\left(1-\mu_{\mathrm{Z}_{l}}^{\mathrm{r}}(.)\right)^{2}+\left(1-\mu_{\mathrm{Z}_{L}}^{\mathrm{r}}(.)\right)^{2}+\left(\mathrm{I}_{2}-\mu_{\mathrm{X}_{l}}^{\mathrm{r}}(.)\right)^{2}\right]^{\frac{1}{2}} \\
\mathrm{r}=1,2, \ldots, \mathrm{R}, l=1,2, \ldots,(L-1)
\end{array}
$$

Where $\left(\mu_{\mathrm{z}_{l}}^{\mathrm{r}}(),. \mu_{\mathrm{z}_{L}}^{\mathrm{r}}(),. \mu_{\mathrm{x}_{l}}^{\mathrm{r}}().\right)$ are the actual utilities resulting from the decision $\mathrm{X}$ under the r-th priority structure of the goals, and $I_{2}$ is the row vector with all elements equal to 1 and the dimension of it depends on $\mathrm{X}, \mathrm{D}^{\mathrm{r}}$ indicates the distance associated between the achieved membership values of the goals and the ideal point when the problem is solved under the r-th priority structure.

In the priority selection process, it can easily be realized that the solution which is closest to the ideal solution point would be the most satisfactory one. As such, priority structure that corresponds to the minimum of the distances obtained for arrangement of different priority structures might be considered as the appropriate priority structure for achievement of goals in the decision making environment.

Here, it can easily be realized that the solution which is closest to the ideal point must correspond to:

$$
\min _{\mathrm{r} \in \mathrm{R}}\left\{\mathrm{D}^{\mathrm{r}}\right\}=\mathrm{D}^{\mathrm{k}} \text { (say), } 1 \leq \mathrm{k} \leq \mathrm{R} .
$$

Then, the k-th priority structure would be considered as an appropriate one to reach the most satisfactory decision in the decision making situation.

Now, it is worthy to note that computational complexity often arises to solve problems with nonlinear objectives/goals by using traditional approximation approaches, and use of such an approach in most of the times leads to a local optimal solution rather than global one. Further, computational load owing to linearization and decision trouble due to approximation error are frequently involved in using conventional methods.

To overcome the above situation, an GA method as a volumeoriented (global one) search method and a promising tool as goal satisficer rather than objective optimizer [33] can be effectively employed to the proposed FGP model to arrive at a reasonable solution for proper distribution of decision powers to the leader and follower in the decision making environment.
Now, in the genetic search process, the fitness function for executing the problem in (7) is defined in section 5.

\section{REPRESENTATION OF EVALUATION FUNCTION}

The goal achievement functions $\mathrm{Z}$ defined in (6) appears as the fitness function in the evaluation process of using the GA. The evaluation function for identification of the fitness of a chromosome can be represented as:

$$
\begin{aligned}
\operatorname{eval}\left(\mathrm{E}_{v}\right)_{\mathrm{r}}=\left(\mathrm{Z}_{\mathrm{r}}\right)_{v}= & \left(\sum_{l=1}^{L} \mathrm{~W}_{\mathrm{r} l}^{-} \mathrm{d}_{\mathrm{r} l}^{-}+\sum_{i=\mathrm{L}+1}^{2 L-1} \mathrm{~W}_{\mathrm{ri}}^{-} \mathrm{d}_{\mathrm{ri}}^{-}\right)_{v} \\
& v=1,2, \ldots, \text { pop_size }
\end{aligned}
$$

where $\left(Z_{r}\right)_{v}$ is used to represent the achievement function $\mathrm{Z}$ in (6) for measuring the fitness value of $v$-th chromosome, when the problem of achieving the goals at the r-th priority level $\mathrm{P}_{\mathrm{r}}$ are taken into account.

In the decision search process, the chromosome $\mathrm{E}^{*}$ with the best fitness value at each generation is determined as:

$$
\mathrm{E}^{*}=\min \left\{\operatorname{eval}\left(\mathrm{E}_{v}\right)_{\mathrm{r}} \mid v=1,2, \ldots, \text { pop_size }\right\}, \mathrm{r}=1,2, \ldots, \mathrm{R} \text {. in the }
$$
genetic search process.

In the solution process, step by step execution of the problem by employing the GA scheme for achievement of model goals on the basis of priorities is briefly discussed as follows.

At the first step, the execution is only performed for searching the minimum of $Z_{1}$ in order to achieve the aspired levels of goals at the first priority level $\left(\mathrm{P}_{1}\right)$ in the domain of solution search space. When minimum of $Z_{1}$ is reached, i.e., the value $\mathrm{Z}_{1}^{*}$ is achieved for a chromosome at a certain generation, the functional expression of the achievement function $\mathrm{Z}_{1}$ is crisply introduced into the system by incorporating $Z_{1}^{*}$ as its upperbound, which acts as insurance against deterioration of the achieved values of goals at the priority level $\mathrm{P}_{1}$ for any further execution to be made for evaluation of the problem. Then, execution counter is shifted to the next step to evaluate $Z_{2}$ for achievement of aspired levels of goals included at the second priority level $\left(\mathrm{P}_{2}\right)$. The continuation of execution for searching solution with sequential selection of priorities (step by step) is made until the evaluation of $\mathrm{Z}_{\mathrm{R}}$ is completed and thereby the fittest chromosome as a candidate solution for final decision is reached in the decision making environment.

Now, the potential use of the approach is illustrated by numerical examples. The model solutions are also compared with solutions obtained by using other approaches studied previously.

\section{ILLUSTRATIVE EXAMPLES}

Two numerical examples are solved to highlight the effective use of the proposed approach.

\section{Example 1:}

A trilevel programming problem (TLPP) is presented as follows.

Find $\left(\mathrm{x}_{1}, \mathrm{x}_{2}, \mathrm{x}_{3}\right)$ so as to: 


$$
\underset{\mathrm{x}_{1}}{\operatorname{Minimize}} \mathrm{Z}_{1}=4 \mathrm{x}_{1}+2 \mathrm{x}_{2}+\mathrm{x}_{3}
$$

(Top-level problem)

where, for given $\mathrm{x}_{1}, \mathrm{x}_{2}$ and $\mathrm{x}_{3}$ solve

$$
\underset{x_{2}}{\operatorname{Minimize}} \mathrm{Z}_{2}=2 \mathrm{x}_{1}+3 \mathrm{x}_{2}+4 \mathrm{x}_{3}
$$

(Middle-level problem)

where, for given $\mathrm{x}_{1}$ and $\mathrm{x}_{2}, \mathrm{x}_{3}$ solves

$$
\text { Minimize } Z_{3}=3 x_{1}+x_{2}+2 x_{3}
$$

(Bottom-level problem)

subject to $\mathrm{x}_{1}+\mathrm{x}_{2}+\mathrm{x}_{3} \geq 1$,

$$
\begin{aligned}
& 2 x_{1}+x_{2}+x_{3} \geq 5, \\
& -x_{1}-x_{2}+3 x_{3} \leq 3, \\
& x_{1}, x_{2}, x_{3} \leq 10 \\
& x_{1}, x_{2}, x_{3} \geq 0
\end{aligned}
$$

Now, to establish the FGP model of the problem as well as to solve it by employing the proposed GA scheme, the following genetic parameter values are incorporated in the decision search process.

- $\quad$ population size $=100$

- $\quad$ probability of crossover $=0.8$

- probability of mutation $=0.08$

- Generation number $=100$

The GA is implemented using Optimization Toolbox in MATLAB (Version 7.10.0.499 (R2010a)). The execution is made in an Intel Pentium IV processor with $2.66 \mathrm{GHz}$. clockpulses and 4 GB RAM.

Note 1 In the context of setting the GA parameter values to solve the problem, it may be mentioned that they are actually adopted from the test results. Here, the parameter setting is particularly adopted to avoid any early convergence with suboptimal decision and substantial increase in generation numbers in the decision making horizon.

Considering the genetic viability of the members in a gene pool of the search domain, it may be noted that the ranges $0.6 \leq \mathrm{p}_{\mathrm{c}}$ $\leq 0.9$ and $0.06 \leq \mathrm{p}_{\mathrm{m}} \leq 0.09$ are also valid for making appropriate decision; otherwise inferior decisions are achieved there under each of the three given priority structures of the test model in the decision making situation. Again, inferior result occurs for selection of pop_ size below 50, and number of generations is considerably increased for any value higher than the adopted one to reach the decision.

However, it is worthy to mention here that the selection of GA parameter values highly depends on the characteristics as well as size of a problem in the decision making environment.

Now, following the procedure, the individual optimal solutions of the three successive levels are obtained as:

(i) $\left(\mathrm{x}_{1}^{1}, \mathrm{x}_{2}^{1}, \mathrm{x}_{3}^{1} ; \mathrm{Z}_{1}\right)=(0,3,2 ; 8)$

(Top-level) (ii) $\left(\mathrm{x}_{1}^{2}, \mathrm{x}_{2}^{2}, \mathrm{x}_{3}^{2} ; \mathrm{Z}_{2}\right)=(2.5,0,0 ; 5)$

(Middle-level)

(iii) $\left(\mathrm{x}_{1}^{3}, \mathrm{x}_{2}^{3}, \mathrm{x}_{3}^{3} ; \mathrm{Z}_{3}\right)=(0,5,0 ; 5)$

(Bottom-level)

Then, the fuzzy goals are defined as:

$$
\mathrm{Z}_{1} \lesssim 8, \mathrm{Z}_{2} \lesssim 5, \mathrm{Z}_{3} \lesssim 5
$$

Following the procedure, the upper-tolerance limits of the objective goals are determined as:

$$
\mathrm{Z}_{1}^{2}=67.66, \mathrm{Z}_{2}^{3}=80.66, \mathrm{Z}_{3}^{\mathrm{m}}=55.33 .
$$

Then, the top-level and middle-level DMs feel that their control variables $\mathrm{x}_{1}$ and $\mathrm{x}_{2}$ should be relaxed up to 0.5 and 1 , respectively, for the benefit of the respective upper-level DMs, and not beyond them. So, $\mathrm{x}_{1}^{\mathrm{n}}=0.5\left(\mathrm{x}_{1}^{2}>0.5>\mathrm{x}_{1}^{1}\right)$ and $\mathrm{x}_{2}^{\mathrm{n}}=1\left(\mathrm{x}_{2}^{3}>1>\mathrm{x}_{2}^{2}\right)$ act as lower tolerance limits of the decisions $\mathrm{x}_{1}$ and $\mathrm{x}_{2}$, respectively.

Now, following the procedure and using the above numerical values, the membership functions of the defined fuzzy goals can be constructed by (3), (4) and (5). Following the procedure, the membership goals are then obtained as:

$$
\begin{aligned}
& \mu_{\mathrm{z}_{1}}: \frac{67.66-\left(4 \mathrm{x}_{1}+2 \mathrm{x}_{2}+\mathrm{x}_{3}\right)}{59.66}+\mathrm{d}_{1}^{-}-\mathrm{d}_{1}^{+}=1 \\
& \mu_{\mathrm{z}_{2}}: \frac{80.66-\left(2 \mathrm{x}_{1}+3 \mathrm{x}_{2}+4 \mathrm{x}_{3}\right)}{75.66}+\mathrm{d}_{2}^{-}-\mathrm{d}_{2}^{+}=1 \\
& \mu_{\mathrm{z}_{3}}: \frac{55.33-\left(3 \mathrm{x}_{1}+\mathrm{x}_{2}+2 \mathrm{x}_{3}\right)}{50.33}+\mathrm{d}_{3}^{-}-\mathrm{d}_{3}^{+}=1 \\
& \mu_{\mathrm{x}_{1}}: \frac{2.5-\mathrm{x}_{1}}{2}+\mathrm{d}_{4}^{-}-\mathrm{d}_{4}^{+}=1 \\
& \mu_{\mathrm{x}_{2}}: \frac{5-\mathrm{x}_{2}}{4}+\mathrm{d}_{5}^{-}-\mathrm{d}_{5}^{+}=1 \\
& \mathrm{~d}_{\mathrm{q}}^{+}, \mathrm{d}_{\mathrm{q}}^{-} \geq 0, \mathrm{q}=1,2, \ldots, 5 .
\end{aligned}
$$

The executable FGP model of the problem can be obtained by using (6).

Following the proposed approach, three priority factors $\mathrm{P}_{1}, \mathrm{P}_{2}$ and $P_{3}$ are assigned to the model goals in (11) for achievement of the associated fuzzy goals, and three priority structures are considered to perform sensitivity analysis in the process of solving the problem in the environment of the given system constraints in (10).

The priority achievement functions under the three Runs and the results obtained by employing the GA scheme with the consideration of the evaluation function defined in (9) are displayed in Table 1. 
Table 1. Priority structure and solution achievement

\begin{tabular}{|c|c|c|c|}
\hline $\begin{array}{c}\mathbf{R u} \\
\mathbf{n}\end{array}$ & $\begin{array}{l}\text { Priority structure for } \\
\text { goal achievement }\end{array}$ & $\begin{array}{l}\text { Decision } \\
\mathrm{x}_{1}, \mathrm{x}_{2}, \mathrm{x}_{3}\end{array}$ & $\begin{array}{c}\text { Membership } \\
\text { value } \\
\mu_{z_{1}}, \mu_{z_{2}}, \mu_{z_{3}}, \mu_{x_{1}}, \mu_{x_{1}}\end{array}$ \\
\hline 1 & {$\left[\begin{array}{l}\mathrm{P}_{1}\left(\frac{1}{59.66} \mathrm{~d}_{1}^{-}+\frac{1}{75.66} \mathrm{~d}_{2}^{-}\right. \\
\mathrm{P}_{2}\left(\frac{1}{50.33} \mathrm{~d}_{3}^{-}\right) \\
\mathrm{P}_{3}\left(\frac{1}{2} \mathrm{~d}_{4}^{-}+\frac{1}{4} \mathrm{~d}_{5}^{-}\right)\end{array}\right.$} & $\begin{array}{l}(2.50 \\
0.00 \\
0.00)\end{array}$ & $(0.96,1,0.95,0,1)$ \\
\hline 2 & {$\left[\begin{array}{l}\mathrm{P}_{1}\left(\frac{1}{59.66} \mathrm{~d}_{1}^{-}\right), \\
\mathrm{P}_{2}\left(\frac{1}{75.66} \mathrm{~d}_{2}^{-}+\frac{1}{50.33} \mathrm{~d}_{3}^{-}\right. \\
\mathrm{P}_{3}\left(\frac{1}{2} \mathrm{~d}_{4}^{-}+\frac{1}{4} \mathrm{~d}_{5}^{-}\right)\end{array}\right.$} & $\begin{array}{l}(0.50, \\
2.12, \\
1.87)\end{array}$ & $\begin{array}{c}(0.99,0.87,0.95,1 \\
, 0.72)\end{array}$ \\
\hline 3 & {$\left[\begin{array}{l}\mathrm{P}_{1}\left(\frac{1}{59.66} \mathrm{~d}_{1}^{-}+\frac{1}{50.33} \mathrm{~d}_{3}^{-}\right. \\
\mathrm{P}_{2}\left(\frac{1}{75.66} \mathrm{~d}_{2}^{-}\right) \\
\mathrm{P}_{3}\left(\frac{1}{2} \mathrm{~d}_{4}^{-}+\frac{1}{4} \mathrm{~d}_{5}^{-}\right)\end{array}\right.$} & $\begin{array}{l}(0.00 \\
5.00 \\
0.00)\end{array}$ & $(0.96,0.86,1,1,0)$ \\
\hline
\end{tabular}

Now, the Euclidean distances for the achieved membership values under the three successive Runs are obtained as:

$$
\mathrm{D}^{1}=1.0018, \mathrm{D}^{2}=0.3137, \mathrm{D}^{3}=1.0092
$$

The results reflect that the minimum distance corresponds to $\mathrm{D}^{2}=0.3137$

Thus, the priority structure under the Run 2 is an appropriate one to reach the appropriate decision for satisfaction of both the leader and follower in the decision making environment. The resultant decision is

$$
\begin{aligned}
& \left(\mathrm{x}_{1}, \mathrm{x}_{2}, \mathrm{x}_{3}\right)=(0.5,2.12,1.86) \text { with } \\
& \left(\mathrm{Z}_{1}, \mathrm{Z}_{2}, \mathrm{Z}_{3}\right)=(8.12,14.57,7.37)
\end{aligned}
$$

The achieved membership values of the objective goals are:

$$
\mu_{\mathrm{z}_{1}}=0.99, \mu_{\mathrm{z}_{2}}=0.87, \mu_{\mathrm{z}_{3}}=0.95 \text {. }
$$

The solution achieved here is a satisfactory one from the view point of distributing the proper decision powers to the DMs in the decision making environment.

\section{Example 2:}

To expound more the potential use of the method, the TLPP studied by Anandalingam [4] is considered.

Find $\left(\mathrm{x}_{1}, \mathrm{x}_{2}, \mathrm{x}_{3}\right)$ so as to:

$$
\underset{\mathrm{x}_{1}}{\operatorname{Maximize}} \mathrm{Z}_{1}=7 \mathrm{x}_{1}+3 \mathrm{x}_{2}-4 \mathrm{x}_{3} \quad \text { (Top-level problem) }
$$

where, for given $\mathrm{x}_{1}, \mathrm{x}_{2}$ and $\mathrm{x}_{3}$ solve

$$
\text { Maximize } \mathrm{Z}_{2}=\mathrm{x}_{2}
$$

(Middle-level problem)

where, for given $\mathrm{x}_{1}$ and $\mathrm{x}_{2}, \mathrm{x}_{3}$ solves

$$
\begin{array}{r}
\underset{\mathrm{x}_{3}}{\operatorname{Maximize} \mathrm{Z}_{3}=\mathrm{x}_{3}} \quad \quad \text { (Bottom-level problem) } \\
\text { subject to } \mathrm{x}_{1}+\mathrm{x}_{2}+\mathrm{x}_{3} \leq 3 \\
\mathrm{x}_{1}+\mathrm{x}_{2}-\mathrm{x}_{3} \leq 1 \\
\mathrm{x}_{1}+\mathrm{x}_{2}+\mathrm{x}_{3} \geq 1 \\
-\mathrm{x}_{1}+\mathrm{x}_{2}+\mathrm{x}_{3} \leq 1 \\
\mathrm{x}_{3} \leq 0.5 \\
\mathrm{x}_{1}, \mathrm{x}_{2}, \mathrm{x}_{3} \geq 0
\end{array}
$$

To solve the problem in (12), the same GA scheme is applied in the same computational environment

Now, following the procedure, the individual optimal solutions of the three successive levels are obtained as:

(i) $\quad\left(\mathrm{x}_{1}^{1}, \mathrm{x}_{2}^{1}, \mathrm{x}_{3}^{1} ; \mathrm{Z}_{1}\right)=(1.4997,0,0.4998 ; 8.4992) \quad($ Top-level $)$

(ii) $\left(\mathrm{x}_{1}^{2}, \mathrm{x}_{2}^{2}, \mathrm{x}_{3}^{2} ; \mathrm{Z}_{2}\right)=(0.3567,1.000,0.3567 ; 1.000)$

(Middle-level)

(iii) $\left(\mathrm{x}_{1}^{3}, \mathrm{x}_{2}^{3}, \mathrm{x}_{3}^{3} ; \mathrm{Z}_{3}\right)=(0.5522,0.1914,0.50 ; 0.50)$

(Bottom-level)

Then, the fuzzy goals are defined as:

$\mathrm{Z}_{1} \gtrsim 8.4992, \mathrm{Z}_{2} \gtrsim 1, \mathrm{Z}_{3} \gtrsim 0.5$ and $\mathrm{X}_{1} \gtrsim 1.4997, \mathrm{x}_{2} \gtrsim 1$.

Following the procedure, the lower-tolerance limits of the objective goals are determined as:

$$
Z_{1}^{2}=4.0701, Z_{2}^{3}=0.1914, Z_{3}^{m}=0.3567 .
$$

In the decision making situation, $\mathrm{x}_{1}^{\mathrm{n}}=1.35\left(\mathrm{x}_{1}^{2}<1.35<\mathrm{x}_{1}^{1}\right)$ and $\mathrm{x}_{2}^{\mathrm{n}}=0.8\left(\mathrm{x}_{2}^{3}<0.8<\mathrm{x}_{2}^{2}\right)$ are considered the lower tolerance limits of the decisions $\mathrm{x}_{1}$ and $\mathrm{x}_{2}$, respectively.

Now, following the procedure, the membership goals are then obtained as:

$\mu_{\mathrm{z}_{1}}: \frac{7 \mathrm{x}_{1}+3 \mathrm{x}_{2}-4 \mathrm{x}_{3}-4.0701}{4.4291}+\mathrm{d}_{1}^{-}-\mathrm{d}_{1}^{+}=1$ 
$\mu_{\mathrm{z}_{2}}: \frac{\mathrm{x}_{2}-0.1914}{0.8086}+\mathrm{d}_{2}^{-}-\mathrm{d}_{2}^{+}=1$

$\mu_{\mathrm{z}_{3}}: \frac{\mathrm{x}_{3}-0.3567}{0.1433}+\mathrm{d}_{3}^{-}-\mathrm{d}_{3}^{+}=1$

$\mu_{\mathrm{x}_{1}}: \frac{\mathrm{x}_{1}-1.35}{0.1497}+\mathrm{d}_{4}^{-}-\mathrm{d}_{4}^{+}=1$

$\mu_{\mathrm{x}_{2}}: \frac{\mathrm{x}_{2}-0.8}{0.2}+\mathrm{d}_{5}^{-}-\mathrm{d}_{5}^{+}=1$

$\mathrm{d}_{\mathrm{q}}^{+}, \mathrm{d}_{\mathrm{q}}^{-} \geq 0, \mathrm{q}=1,2, \ldots . ., 5$.

subject to the given system constraints in (12).

In an analogous to the previous example, sensitivity analysis for selection of appropriate priority structure is also made here with the consideration of four priority levels. The priority structure for optimal decision is found as:

$\left[\mathrm{P}_{1}\left(\frac{1}{4.4291} \mathrm{~d}_{1}^{-}\right), \mathrm{P}_{2}\left(\frac{1}{0.8086} \mathrm{~d}_{2}^{-}\right), \mathrm{P}_{3}\left(\frac{1}{0.1433} \mathrm{~d}_{3}^{-}\right), \mathrm{P}_{4}\left(\frac{1}{0.1497} \mathrm{~d}_{4}^{-}+\frac{1}{0.2} \mathrm{~d}_{5}^{-}\right)\right]$

The resultant decision for the prescribed priority structure is obtained as:

$$
\begin{aligned}
& \left(\mathrm{x}_{1}, \mathrm{x}_{2}, \mathrm{x}_{3}\right)=(1.2711,0.2288,0.5000) \text { with } \\
& \left(\mathrm{Z}_{1}, \mathrm{Z}_{2}, \mathrm{Z}_{3}\right)=(7.5841,0.2288,0.5000)
\end{aligned}
$$

The achieved membership values of the objective goals are:

$$
\mu_{\mathrm{z}_{1}}=0.8, \mu_{\mathrm{z}_{2}}=0, \mu_{\mathrm{z}_{3}}=1 \text {. }
$$

Here, it is to be followed that the solution of the problem achieved by using the traditional approach in crisp environment is:

$$
\left(\mathrm{x}_{1}, \mathrm{x}_{2}, \mathrm{x}_{3}\right)=(0.5,1,0.5) \text { with }\left(\mathrm{Z}_{1}, \mathrm{Z}_{2}, \mathrm{Z}_{3}\right)=(4.5,1,0.5)
$$

The result indicates that the solution obtained by using the proposed approach is more satisfactory from the view point of distributing the proper decision powers to the DMs in the decision making environment.

\section{PERFORMANCE COMPARISON}

To expound the effectiveness of the proposed method, the model solutions of both the examples are compared with the solutions of the problems obtained previously by using other conventional approaches.

- The Case for Example 1:

a) If the conventional minsum FGP approach [14] is used, where only a weight structure without any priority factor is considered for achievement of fuzzy goals, then the solution is found as:

$$
\begin{aligned}
& \left(\mathrm{x}_{1}, \mathrm{x}_{2}, \mathrm{x}_{3}\right)=(0.7,1.92,1.78) \text { with } \\
& \left(\mathrm{Z}_{1}, \mathrm{Z}_{2}, \mathrm{Z}_{3}\right)=(8.42,14.28,7.58)
\end{aligned}
$$

b) If the minmax FGP approach [34] is used, where maximum importance is given to the goal most displaced from the target level relative to others, then the solution is found as:

$$
\begin{aligned}
& \left(\mathrm{x}_{1}, \mathrm{x}_{2}, \mathrm{x}_{3}\right)=(0.80,1.80,1.80) \text { with } \\
& \left(\mathrm{Z}_{1}, \mathrm{Z}_{2}, \mathrm{Z}_{3}\right)=(8.60,14.20,7.8)
\end{aligned}
$$

c) If the additive-FGP approach studied in [35] is taken into account, where no priority structure is considered and where maximization of $\sum_{\mathrm{k}=1}^{\mathrm{K}} \mu_{\mathrm{k}}$ subject to $\mu_{\mathrm{k}} \leq 1$ and the defined system constraints are taken into account, then the solution of the problem is obtained as:

$$
\begin{aligned}
& \left(\mathrm{x}_{1}, \mathrm{x}_{2}, \mathrm{x}_{3}\right)=(0.65,1.98,1.82) \text { with } \\
& \left(\mathrm{Z}_{1}, \mathrm{Z}_{2}, \mathrm{Z}_{3}\right)=(8.38,14.52,7.57)
\end{aligned}
$$

It is to be noted that the decision of the bottom-level DM is improved under the proposed GA approach with a least sacrifice of the decision of the top-level and middle-level DMs in comparison to that obtained by the conventional FGP approach.

The graphical representations of the goal values of objectives obtained under different approaches are displayed in Fig 2.

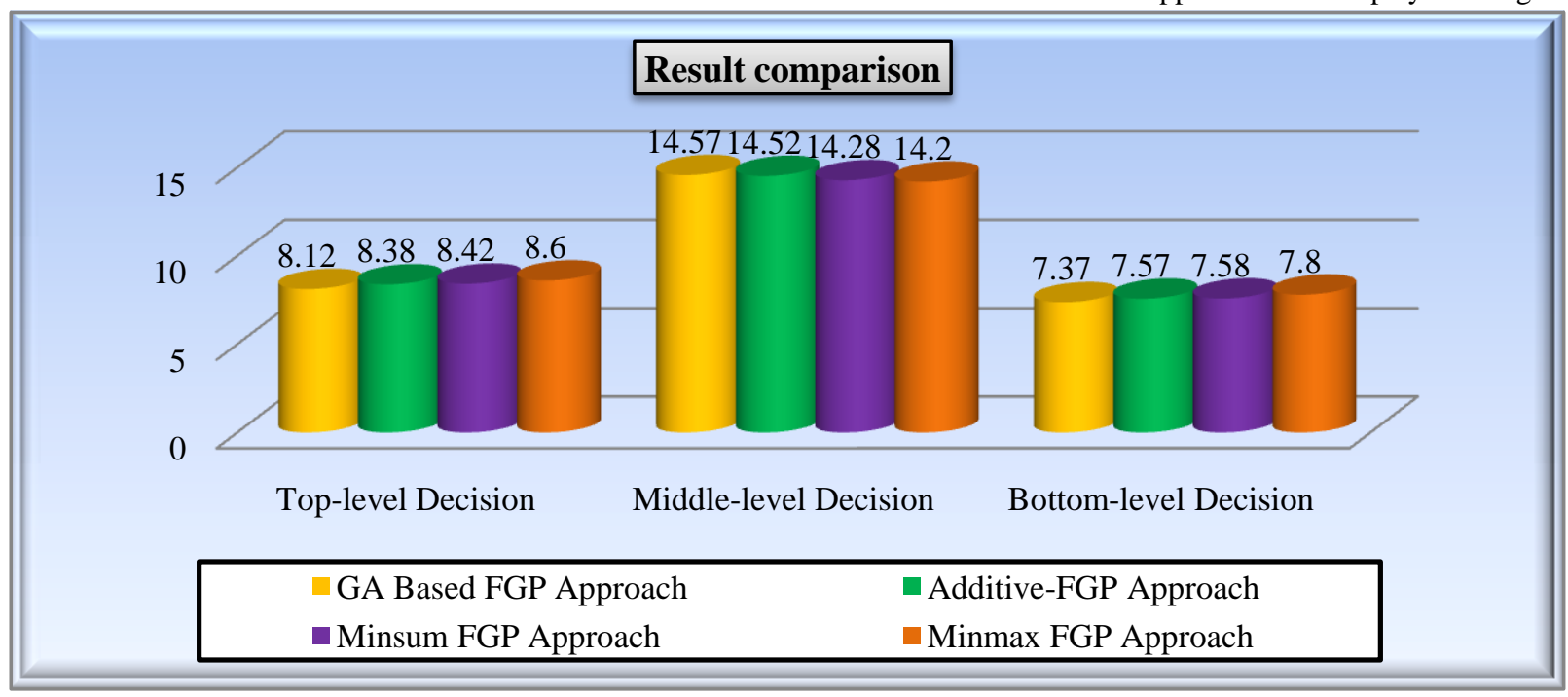

Fig 2: Graphical representation of objective goal achievements under different approaches 
It is apparent that the solution obtained by using the proposed GA to the priority-based FGP formulations of the problem is the most satisfactory one from the viewpoint of arriving at an appropriate decision in the decision environment.

- $\quad$ The Case for Example 2:

In case of example 2, if the approaches minmax FGP, conventional minsum FGP and additive-FGP are successively used, then the solutions are found to be

$$
\begin{gathered}
\left(\mathrm{x}_{1}, \mathrm{x}_{2}, \mathrm{x}_{3}\right)=(1.4997,0.0003,0.5000) \text { with } \\
\left(\mathrm{Z}_{1}, \mathrm{Z}_{2}, \mathrm{Z}_{3}\right)=(8.4988,0.0003,0.5000) \text { and } \\
\left(\mathrm{x}_{1}, \mathrm{x}_{2}, \mathrm{x}_{3}\right)=(0.7032,0.1914,0.3567) \text { with } \\
\left(\mathrm{Z}_{1}, \mathrm{Z}_{2}, \mathrm{Z}_{3}\right)=(4.0701,0.1914,0.3567), \text { respectively. }
\end{gathered}
$$

The graphical representations of the goal values achieved under different approaches are displayed in Fig 3.

$$
\begin{gathered}
\left(\mathrm{x}_{1}, \mathrm{x}_{2}, \mathrm{x}_{3}\right)=(1.0717,0.4282,0,5000) \text { with } \\
\left(\mathrm{Z}_{1}, \mathrm{Z}_{2}, \mathrm{Z}_{3}\right)=(6.7869,0.4282,0.5000),
\end{gathered}
$$

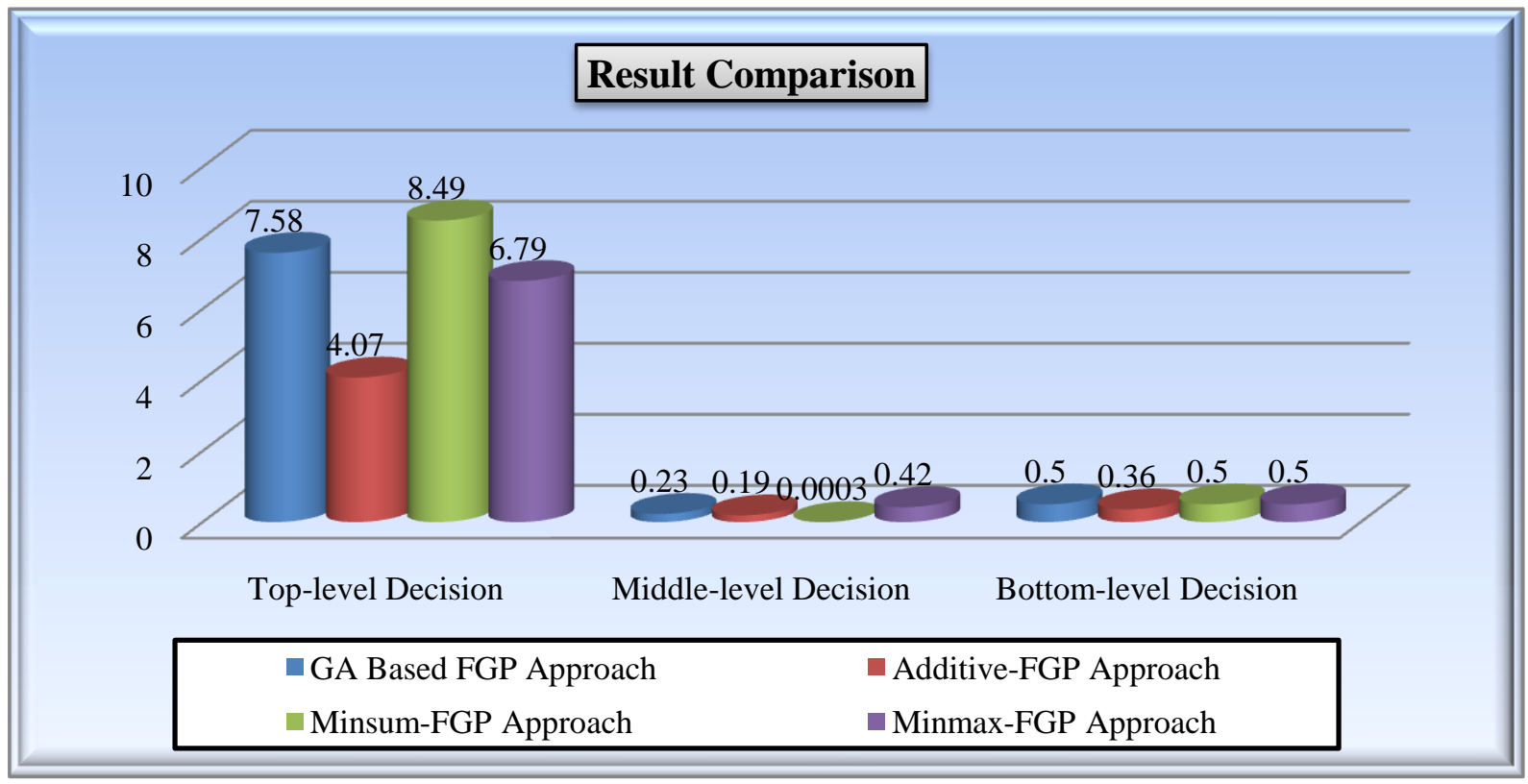

Fig 3: Graphical representation of objective goal achievements under different approaches

The above discussions and solution comparisons reflect that the proposed approach is a superior one over the previous approaches for making appropriate decision with regard to optimizing the objectives in a hierarchical decision environment. Further, the incorporation of Euclidean distances for proper priority selection with the use of GA makes the decision more effective to make a reasonable balance of execution of decision powers of DMs in the decision environment.

\section{CONCLUSIONS AND SCOPE FOR FUTURE RESEARCH}

The main advantage of the proposed approach is that a proper decision can be made here on the basis of relative priority of importance of achieving objectives in a hierarchical order in the decision making situation.

The proposed approach can be extended to solve problems with multiplicity of objectives at each decision level in a hierarchical decision system, which may be a problem in future study.

Finally, it is expected that the FGP approach presented here can contribute to future research to solve real-life multiobjective hierarchical decentralized decision problems in uncertain environment.

\section{REFERENCES}

[1] Sakawa, M. and Nishizaki, I. 2009. Cooperative and Noncooperative Multi-Level Programming. Springer, New York.

[2] Burton, R.M. and Obel, B. 1977. The multilevel approach to organizational issues of the firm-critical review. Omega. $5,395-413$

[3] Bard, J.F. 1983. An algorithm for solving the general bilevel programming problem. Mathematics Operations Research, 8(2), 260 - 272.

[4] Anandalingam, G. 1988. A mathematical programming model of decentralized multi-level systems. Journal of the Operational Research Society, 39, $1021-1033$.

[5] Anandalingam, G. and Apprey, V. 1991. Multi-level programming and conflict resolution. European Journal of Operational Research. 51, $233-247$.

[6] Bard, J.F. 1988. An Investigation of the linear three-level programming problem. IEEE Transactions on Systems Man and Cybernet. SMC 14, 711 - 717. 
[7] Zimmermann, H.-J. 1987. Fuzzy Sets, Decision Making and Expert Systems. Dordrecht, Boston: Kluwer Academic Publishers.

[8] Zadeh, L. A. 1965. Fuzzy sets. Information and Control. 8, $338-353$.

[9] Lai, Y.-J. 1996. Hierarchical optimization: A satisfactory solution. Fuzzy Sets and Systems. 77, 321 - 335.

[10] Bellman, R.E. and Zadeh, L.A. 1970. Decision- making in a fuzzy environment. Management Sciences. 17, B141 B164.

[11] Shih, H.S., Lai, Y.J. and Lee, E. S. 1996. Fuzzy approach for multi-level programming problems. Computers and Operations Research. 23, 73 - 91.

[12] Shih, H.S., Lee, S. 2000. Compensatory fuzzy multiple level decision making. Fuzzy Sets and Systems. 14, 71 - 87.

[13] Pal, B.B., Moitra, B.N. and Maulik, U. 2003. A goal programming procedure for fuzzy multiobjective linear fractional programming problem. Fuzzy Sets and Systems. $139,395-405$.

[14] Ignizio, J.P. 1976. Goal Programming and Extensions. Lexington, Massachusetts: D.C. Health.

[15] Simon, H. A. 1957. Administrative Behavior. New York: Free Press.

[16] Biswas, A. and Pal, B.B. 2004. A fuzzy multilevel programming method for hierarchical decision making. Lecture Notes in Computer Science. 3316, Springer, Berlin, 904 - 911.

[17] Pal, B.B. and Moitra B.N. 2002. A fuzzy goal programming procedure for solving bilevel programming problems. In Pal N.R., Sugeno, M. (eds) AFSS 2002. LNCS (LNAI), 2275, 91--98. Springer, Heidelberg.

[18] Pal, B.B. and Pal, R. 2003. A linear multilevel programming method based on fuzzy programming. Proceedings of APORS 2003, 1, 58-65.

[19] Holland, J.H. 1973. Genetic algorithms and optimal allocation of trials. SIAM Journal of Computing. 2, 88 105.

[20] Goldberg, D. 2002. The Design of Innovation: Lessons from and for Competent Genetic Algorithms. Norwell, MA: Kluwer Academic Publishers.

[21] Gen, M. and Cheng, R. 2000. Genetic algorithm and engineering optimization, New York, John Wiley \& Sons, Inc.
[22] Sakawa, M., Nishizaki, I. and Hitaka, M. 2001. Interactive fuzzy programming for multi-level 0-1 programming problems with fuzzy parameters through genetic algorithms. Fuzzy Sets and Systems. 117 ( 1), 95-111.

[23] Hejazi, S. R., Memariani, A., Jahanshahloo, G. and Sepehri, M. M. 2002. Linear bilevel programming solution by genetic algorithm. Computers and Operations Research. 2 (29), $1913-1925$.

[24] Zheng, D., Gen, W.M. and Ida, K. 1996. Evolution program for nonlinear goal programming. Computers and Industrial Engineering. 31 (3-4), 907-911.

[25] Gen, M., Ida, K., Lee, J. and Kim, J. 1997. Fuzzy nonlinear goal programming using genetic algorithm. Computers and industrial Engineering. 33(1-2), 39-42.

[26] Sakawa, M. and Kobuta, R. 2000. Fuzzy programming for multiobjective job shop scheduling with fuzzy processing item and fuzzy due data through genetic algorithms. European Journal of Operations Research. 120(2), 393407

[27] Taguchi, T., Ida, K. and Gen, M. 1998. A genetic algorithm for optimal flow assignment in computer network. Computers and Industrial Engineering. 35(3-4), 535-538.

[28] Wang, Y.Z. 2002. An application of genetic algorithm methods for teacher assignment problems. Expert Systems with Applications. 22(4), 295-302.

[29] Goldberg, D.E. 1989. Genetic Algorithms in Search, Optimization and Machine Learning. USA: AddisonWesley Longman Publication.

[30] Tiwari, R.N., Dharmar, S. and Rao, J.R. 1986. Priority structure in fuzzy goal programming. Fuzzy Sets and Systems. 19(3), 251 - 259.

[31] Pal, B.B. and Moitra, B.N. 2003. A goal programming procedure for solving problems with multiple fuzzy goals using dynamic programming. European Journal of Operational Research. 144, 480 - 491.

[32] Yu, P L. 1973. A class of solutions for group decision problems. Management Science. 19, 936 - 946.

[33] Deb, K. 2002. Multiobjective Optimization Using Evolutionary Algorithm. United States: John Wiley and Sons Ltd.

[34] Romero, C. 1991. Handbook of Critical Issues in Goal Programming. Oxford: Pergamon Press.

[35] Tiwari, R.N., Dharmar, S. and Rao, J.R. 1987. Fuzzy goal programming - an additive model. Fuzzy Sets and Systems. 24(1), 27 - 34. 